\title{
Visual Arabic Word Recognition during Subliminal and Supraliminal Presentations: A Lexical Decision Study in Normal and Disabled Readers
}

\author{
Shaden Shuhaiber Rizik ${ }^{1,2,3^{*}}$, Asaid Khateb1,2, Alan J. Pegna ${ }^{4}$ \\ ${ }^{1}$ The Unit for the Study of Arabic Language, Edmond J. Safra Brain Research Center for the Study of Learning Disabilities, \\ University of Haifa, Haifa, Israel \\ ${ }^{2}$ Department of Learning Disabilities, Faculty of Education, University of Haifa, Haifa, Israel \\ ${ }^{3}$ Department of Special Education, The Arab Academic College for Education, Haifa, Israel \\ ${ }^{4}$ School of Psychology, University of Queensland, Queensland, Australia \\ Email: *shaden.shuhaiber@gmail.com, akhateb@edu.haifa.ac.il, a.pegna@uq.edu.au
}

How to cite this paper: Rizik, S. S., Khateb, A., \& Pegna, A. J. (2021). Visual Arabic Word Recognition during Subliminal and Supraliminal Presentations: A Lexical Decision Study in Normal and Disabled Readers. Open Journal of Modern Linguistics, 11, 361-379.

https://doi.org/10.4236/ojml.2021.113028

Received: April 26, 2021

Accepted: June 5, 2021

Published: June 8, 2021

Copyright () 2021 by author(s) and Scientific Research Publishing Inc. This work is licensed under the Creative Commons Attribution International License (CC BY 4.0).

http://creativecommons.org/licenses/by/4.0/

\section{(c) (i) Open Access}

\begin{abstract}
This study aimed at assessing visual word recognition in normal skilled (NRs) and disabled adult Arabic readers (DRs) using masked subliminal and supraliminal word presentations in a lexical decision task (LDT). The main assumption of this investigation was that, as a consequence of their reading disability, DRs would exhibit slower reaction times (RTs) and lower performance than NR in the supraliminal condition. By contrast, since words identified subliminally are thought to occur thanks to advanced orthographic (not phonological skills), it was assumed that this presentation mode would diminish the differences between DRs and NRs. RTs and $d$ detection measures were analyzed in 59 NRs and 21 DRs who had to decide whether visually presented letter strings corresponded to real Arabic words or to pseudowords. The statistical analyses conducted on RTs and $d$ showed that, although both groups showed a lexicality effect (faster RTs for words than for pseudowords), the DRs compared to NRs showed longer RTs and lower detection measures in the supraliminal mode. Importantly, in the subliminal mode, no group effect was found in terms of RTs and the size of the difference between groups in terms of detection decreased. Also, in this latter presentation condition, we observed that the lexicality effect was significant in the DRs but not in the NRs. These findings are discussed in relation to other studies indicating that DRs might have benefited from good orthographic skills, on which they rely to compensate for their phonological deficits.
\end{abstract}




\section{Keywords}

Consciousness, Lexicality, Word Processing, Dyslexia, Signal Detection

\section{Introduction}

In our daily life we encounter endless experiences and challenges that bombard us with subliminal effects, which can change consciously or unconsciously the course of our stream of thoughts and in doing so affect our behavior. In the current paper we were interested in examining how deeply visual orthographic stimuli can be processed in normal (NR) and disabled (DR) young readers, in the absence of consciousness. Subliminal processing Cognitive psychology has addressed unconscious perceptual processing using a number of different paradigms, one being "Subliminal Perception". In this approach, information is presented beneath or slightly below the threshold of perceptual detection, so as to impede conscious processing (Cleeremans \& McClelland, 1991). Additionally, visual masking is often included. This technique, previously described by Enns and Di Lollo (2000), ensures a reduction in the visibility of the stimulus when it is preceded or followed by the presentation of another stimulus to be detected. Kiesel et al. (2006) noted that, despite the ability to report the stimuli, subliminally presented cues have the ability to influence behavioral choices. It has been suggested that conscious decisions are affected by nonconscious processes and that such effects can be observed after delays of at least 25 minutes (Ruch et al., 2016), indicating a considerable longevity of the phenomenon on intentional behavior and decision-making.

\section{The Dual Route Model of Reading and Disabled Readers}

Unconscious processing may shed light on the processes underlying word recognition in DRs. The Dual Route Model of Reading (Coltheart, 2005; Coltheart, Rastle, Perry, Langdon, \& Ziegler, 2001) proposes that reading a written word is performed through one of two routes. In the first route that is called the "Lexical Route", the processing and the pronunciation of the written word are performed through the use of the mental database that contains this specific word. This route includes three components: the semantic system that contains the meaning of the words, and the general lexicon which contains the orthographic and the phonological lexicons or components. The activation of one of the lexicons leads inevitably to the activation of the other such as, for example the word "cat" is orthographically read $\langle\mathrm{c}, \mathrm{a}, \mathrm{t}\rangle$, activating the phonological representation $\langle\mathrm{K}$.T $\rangle$. When relying on this route, the reader recognizes and names words with high lexical frequency more rapidly than those with low lexical frequency. On the other hand, the other route termed the "Non-Lexical Route" is used for the pronunciation of the string of letters through the application of grapheme-to-phoneme conversion rules. The process happens sequentially according to the following scheme: the activation of the second phoneme 
does not begin until a certain number of circles have been activated following the activation of the first letter (for instance: the pseudoword "bant" activates first $\{\mathrm{B}: / \mathrm{b} /, \mathrm{A}: / \mathrm{a} /\}$, then $\{\mathrm{N}: / \mathrm{n} /\}$, and $\{\mathrm{T}: / \mathrm{t} /\})$. According to Coltheart et al. (2001), the longer processing time taken by this route is a direct result of the sequential process in substituting morphemes with phonemes, a process that is even longer when naming low frequency words and pseudowords (see for instance Bentin and Ibrahim, 1996). The difference in processing times of words and pseudowords is based on the assumption that words can be read and named through a direct access to the lexicon using the complete orthographic word code that immediately makes available the entire phonological information for naming, whereas the pronunciation of pseudoword is achieved through a serial, longer and less efficient processing of prelexical phonological components. Therefore, this model proposes that known words are processed through the lexical route while unknown new words and pseudowords that are not stocked in the orthographic lexicon are decoded through the non-lexical or the phonological route.

The dual-route model of reading, developed already in 1970s (Coltheart, 2005) has been frequently reviewed (Coltheart et al., 2001) and used to explain various aspects of normal reading, as well as developmental and acquired (i.e., following brain injury) reading difficulties. For instance, a large body of research has been carried out to understand the causal basis and reading mechanisms in developmental dyslexia (DD), which is generally diagnosed in childhood but persists into adulthood (e.g., Elbro, Nielsen, \& Petersen, 1994; Miller-Shaul, 2005; Pratt \& Bradly, 1988; Shankweiler, Crain, Brady, \& Macaruso, 2017). In this context, it has been argued that the surface manifestations of dyslexia in the different languages may vary depending on the languages' specific orthographic conventions and reading rules (Wimmer, 1993). For many authors, the phonological processing deficit appeared as the strongest causal factor of DD (e.g., Stanovich \& Siegel, 1994; Wagner \& Torgesen, 1987; Wolf \& Bowers, 1999). However, different studies have also favored a broader theoretical basis for this developmental condition. Behavioral studies had suggested that the speed of word recognition, and not accuracy alone, might provide additional valuable information about word recognition processes (Bowey \& Muller, 2005; Manis, 1985; Suárez-Coalla, Ramos, Álvarez-Cañizo, \& Cuetos, 2014). In accordance with this view, different investigations have reported that dyslexics were slower in recognizing words, a difficulty that was seemingly linked with their slowness when naming objects, colors, digits and letters' (e.g., Bowers \& Wolf 1993; Felton \& Wood, 1989). Some researchers argued that such slowness might constitute another core-deficit in disabled readers (e.g., Torgesen, Wagner, Simmons \& Laughon, 1990). In fact, a fluency deficit has been introduced in the recent definitions of dyslexia. Fletcher (2009) has suggested that some dyslexics, while not exhibiting word reading and decoding problems, show difficulties in reading words and text automatically. Actually, the most prominent feature of adulthood dyslexia in regular orthographies is the slowness in single word recognition and not the accuracy deficits 
observed more usually in childhood dyslexia (Ben-Dror, Pollatsek, \& Scarpati, 1991; Bruck, 1992; Lefly \& Pennington, 1991; Miller-Shaul, 2005). Also, Siegel, Share and Geva (1995) demonstrated that DR performed better than NR in orthographic awareness tasks, and proposed that dyslexics adopt reading strategies that rely on visual features which allow them to compensate for their phonological deficits. In addition, it was reported that, compared to controls, adult dyslexics showed a preference for visual screening strategies when faced with a matching task with words and non-words, whereas their non-dyslexic peers used phonological rehearsing strategies for the same task (Shafrir \& Siegel, 1994). Along the same line, Abu-Rabia et al. (2003) reported that the performance of reading-disabled children on orthographic processing measures was as good as that of the NRs (Abu-Rabia, Share, \& Said Mansour, 2003).

Lexical decision tasks have been widely used to assess orthographic skills in NRs and DRs (Olson, Forsberg, Wise, \& Rack 1994). In one study, Leinonen, Muller, Leppanen, Aro, Ahonen, \& Lyytinen (2001) presented Finnish DR and NR with two lexical decision tasks with a visual masking technique. In Leinonen et al.'s (2001) study, two rapid orthographic processing tasks with both word and pseudoword stimuli were presented for brief durations (60 ms and $80 \mathrm{~ms}$ ), followed by $80 \mathrm{~ms}$ backward masking stimulus in order to examine the participants' use of orthographic processes and to minimize their utilization of phonological processes. The researchers identified a subgroup of DRs who practiced advanced orthographic skills and who performed better than the other dyslexic participants in their lexical decision abilities. This latter group was reported as practicing intensive reading habits (i.e., large exposure to print), that were previously suggested to improve the dyslexics' identification of the words (Stanovich \& Siegel, 1994). McPherson et al. (1998) distinguished between two groups of dyslexics on the basis of their scores in a nonword reading test. The first, named the dysphonic group, showed intact abilities in the orthographic priming task but very weak abilities in the phonological priming tasks, while the second, named the phonetic group, displayed the exact opposite pattern of abilities. Shany and Breznitz (2011) investigated cognitive and linguistics skills in subtypes of adult dyslexics and found that, relative to accuracy-disabled subgroup who showed low orthographic skills, rate-disabled subgroup performed normally and compared to NR in orthographic tasks.

In word recognition and word naming studies, priming paradigms have often been used and semantic facilitation was found even when the stimuli, including words, numbers or novel stimuli, were presented subliminally (see for review Van den Bussche, Van den Noortgate, \& Reynvoet, 2009). A neuroimaging study showed that processing of subliminally presented words (although not reaching consciousness) induced activity in the occipital cortex and left fusiform gyrus and pre-central cortex (Dehaene, Naccache, Cohen, Bihan, Mangin, Poline, \& Riviere, 2001). It was also shown that the manipulation of the presentation mode such as to induce unconscious processing allowed distinguishing between emotional and neutral words (Gaillard, Del Cul, Naccache, Vinckier, Cohen, \& De- 
haene, 2006). Other studies showed that masked visual primes unconsciously affected participants' performance in semantic categorization (Kiesel et al., 2006; Ocampo, 2015).

In this study, word recognition was studied in Arabic-speaking adult dyslexics using a lexical decision task that manipulated the time of presentation of the stimuli. To date, studies attempting to identify the core deficit behind dyslexia in the Arabic language have emphasized the role of the phonological difficulties exhibited by both child and adult dyslexic individuals (Abu-Rabia et al., 2003; Abu-Rabia \& Siegel, 2002). This investigation used supraliminal and subliminal stimulus durations with backward pattern masks to manipulate the time of presentation of the word stimuli, under the assumption that subliminal presentation will allow automatic processing to occur without awareness (Fairhall, Hamm, \& Kirk, 2007; Kouider \& Dehaene, 2007; Pegna, Landis, \& Khateb, 2008; Van den Bussche et al., 2009). For this purpose, a simple speeded lexical decision task with words and pseudowords in the two modes of stimulus presentation (i.e., supraliminal and subliminal) was used. Based on previous research (Abu-Rabia et al., 2003) suggesting that good orthographic abilities of Arabic-speaking adult DRs might allow them to use the visual-orthographic lexical route to compensate for their phonological difficulties, this study assumed that DR's word recognition accuracy might be improved if it occurs more automatically and without relying on their phonological skills. Automatic processing is hypothetically possible under conditions of subliminal presentation of the stimuli where the DR participants, exactly like NRs, will be unable to access information through bottom-up activation processes. Accordingly, the two main working hypotheses of this study were that: 1) in the supraliminal presentation mode, NRs would exhibit faster reaction times (RTs) and higher detection abilities for real words than the DRs and that 2) in the subliminal mode the gap will be reduced between the recognition level of DRs and NRs. More generally, as could be expected in lexical decision tasks, it was predicted that both the DRs and NRs would show shorter RTs for words than for nonwords (i.e., a lexicality effect, see Coltheart, 2005) and also higher accuracy for words than for pseudowords (Bentin \& Ibrahim, 1996; Khateb, Khateb-Abdelgani, Taha, \& Ibrahim, 2014; Khateb, Taha, Elias, \& Ibrahim, 2013).

\section{Material and Methods}

\subsection{Participants}

Eighty young native Arabic speakers (49 women) from the north of Israel participated in the study. These included 59 normal readers (NR) and 21 disabled readers (DR). The NR were students from the University of Haifa (mean age, $M$ $=22.4, S D=2.0$ ). The DR were recruited from specialized schools and diagnosed as developmentally disabled readers. All participants were right-handed (according to the Edinburgh Inventory, Oldfield, 1971, $M=0.6, \pm S D=0.35$ ) and had normal or corrected-to-normal vision. All participants gave their informed 
written consent. The NR were paid for their participation (35 ILS/hour) while the DR were tested in the context of their school and were rewarded with a voucher for the same amount.

\subsection{Screening Tests}

The DRs were screened for their reading abilities, phonological abilities, working memory and speed of information processing (Rapid automatic naming tests; RAN, Denckla \& Rudel, 1976). The performance of the DRs (age, $M=17.8, S D=$ $0.7)$ in these tests were compared with that of a group of 21 aged-matched NR participants (age, $M=17.9, S D=0.4, p=0.71$ ) that are not part of the lexical decision experiment study (see Table 2).

Vowelized pseudowords: The participants were asked to read aloud a list of 40 vowelized pseudowords, as quickly and accurately as possible. Reading speed and accuracy rate were measured.

Vowelized words: The participants were asked to read aloud a list of 40 vowelized words, as quickly and accurately as possible. Reading speed and accuracy were measured.

Text reading tests: The participants were asked to read aloud a text which consisted of 137 words. The text was chosen to match the reading age of the participants for normal reading. Reading accuracy and speed were measured.

Rapid automatized naming: This RAN test measured the speed of naming of objects, letters and numbers and evaluated the speed of information processing (Denckla \& Rudel 1976). In each of the sub-tests (i.e., letters, numbers and pictures), the participant had to name a series of 50 items (the same 5 items repeated 10 times). Response times (in seconds) were measured for each subtest and then all averaged for each participant.

Phonological segmentation: This test examined the participants' phonological awareness. They were asked to segment 20 words and 20 pseudowords into their phonemic elements (basic sounds) (Taha \& Saiegh-Haddad, 2016). The percentage of correctly segmented items and the total time for each list were measured for each participant.

Simple and double choice reaction time tasks: Given the fact that the LDT used here rely on speeded responses, we used two computerized reaction time tasks to compare the speed of information processing of DRs and NRs. The rational was to assess to what extent possible differences in word recognition times might be accounted for by a general slowness. As shown in Figure 1, in the simple reaction time task (SRT), the participants were asked to respond as rapidly as possible to the appearance of an $\mathrm{X}$ in the center of the computer screen. They responded using a button press with their right index finger. Each trial started with a "bip" (as a warning signal), which was followed by $500 \mathrm{~ms}$ blank screen, then the X appeared until the participant's response (for a maximum of 2000 $\mathrm{ms}$ ), that was followed by an inter-stimulus interval of $500 \mathrm{~ms}$. In the doublechoice reaction time task (DRT) that used the same procedure, the participants 

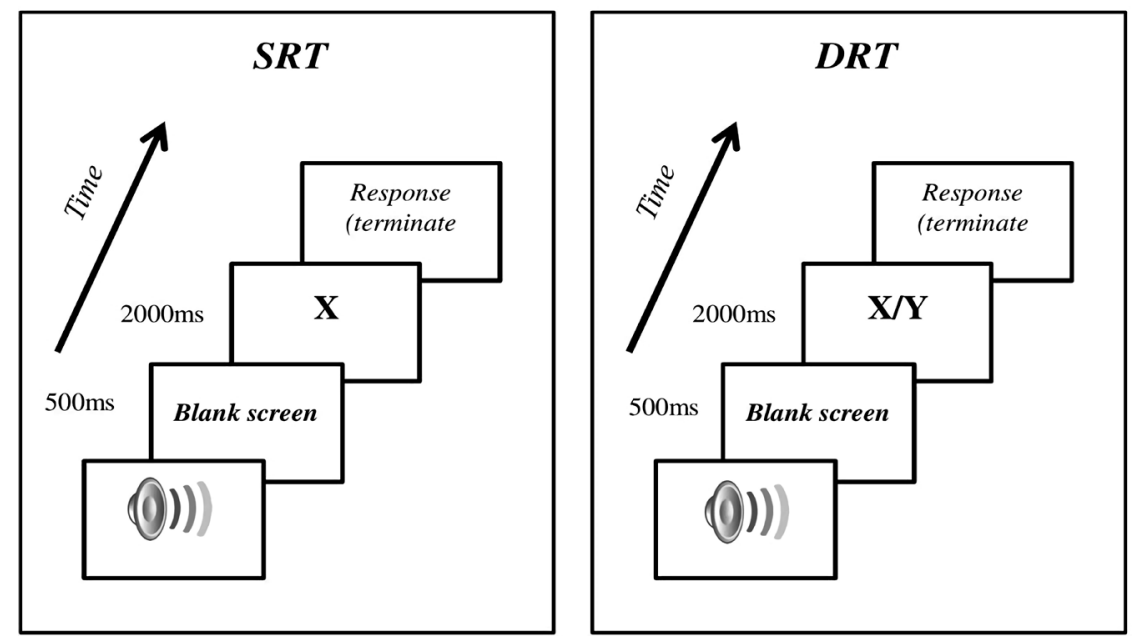

Figure 1. Schematic presentation of the sequence of events in the simple reaction time task (SRT) where the participants had to respond rapidly to the presentation of the stimulus $\mathrm{X}$ and for the double reaction time task (DRT) where they had to respond randomly to X and Y which appeared for $2000 \mathrm{~ms}$ after an alarming "bip" and a $500 \mathrm{~ms}$ blank screen.

were presented either with $\mathrm{X}$ or with $\mathrm{Y}$ and had to respond using one button press for the appearance of the $\mathrm{X}$ and another press for the Y. In both tasks, the individual mean RTs were computed relative to the stimulus onset. In the SRT, there were 30 trials for the stimulus $\mathrm{X}$ and in the DRT there were 30 trials for each stimulus.

\subsection{Lexical Decision Experimental Procedure}

The stimulus list for the lexical decision task was composed of a total of 320 items: Half of them were words $(\mathrm{W}, N=160)$ and the other half pseudowords (PW, $N=160)$. The words were all Arabic nouns (160, half concrete and half abstract nouns) of 3 to 6 letters' length (word length $M=3.8, \pm S D=0.97$ ). For the stimuli selection, a questionnaire containing a total of 215 concrete and abstract nouns was filled by 30 Arabic speaking adults in order to assess word familiarity. The participants were asked to rate the familiarity using a 0 to 5 scale ( 0 for word not familiar/frequent and 5 for highly familiar/frequent). The average frequency for each of the 215 words was computed, and based on this analysis the final list of 160 words was created using middle to high frequency items $(M=3.43, \pm S D=0.72)$. The phonologically plausible pseudowords (PW) were produced by altering the beginning, middle or the final letter of a real word, keeping exactly the same length as in real words (see examples in Table 1).

The participants were required to make a speeded lexical decision (LDT) on visually presented words and pseudowords that appeared randomly on the center of the computer screen. Each trial (of total duration of $\sim 2520 \mathrm{~ms}$ ) started with a fixation for $500 \mathrm{~ms}$, then by the presentation of a stimulus (either W or PW), followed by a visual mask (a series of Greek letter strings) and then a blank screen to allow for the participants' responses. As shown in Figure 2, in the supraliminal 
Table 1. Summary of the experimental conditions and examples of stimuli with English translation and phonological translation for real words and phonological translation for pseudowords.

\begin{tabular}{|c|c|c|c|}
\hline & Arabic & Phonetic & English \\
\hline \multirow{3}{*}{ Words } & بطاطا & bata:ta: & Potato \\
\hline & 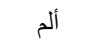 & a:lam & Pain \\
\hline & كلَج & $\theta$ alj & Snow \\
\hline \multirow{3}{*}{ Pseudowords } & بَطاطَ & bata:tam & \\
\hline & ألَّش & a:la $\int$ & \\
\hline & تَكَف & $\theta$ alaf & \\
\hline
\end{tabular}

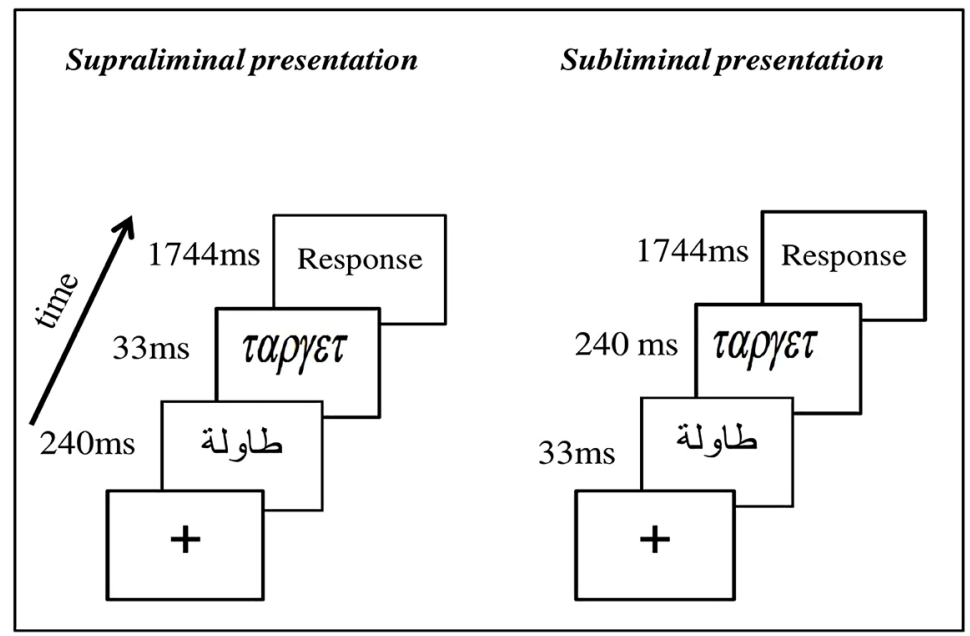

Figure 2. Illustration of the experimental procedure. The stimuli (Word or Nonword) appeared after a fixation cross for either $240 \mathrm{~ms}$ or $33 \mathrm{~ms}$ (supraliminal vs. subliminal). Words were presented centrally followed by a visual mask (of $33 \mathrm{~ms}$ or $240 \mathrm{~ms}$ ) and then a blank screen allow the subjects to respond.

presentation the stimulus appeared for $240 \mathrm{~ms}$ followed by a $33 \mathrm{~ms}$ visual mask then a blank screen (varying between $1640-1840 \mathrm{~ms}, M=1744 \mathrm{~ms}$ ) allowed for the participant's response. In the subliminal presentation, the stimulus appeared for $33 \mathrm{~ms}$ and was followed by $240 \mathrm{~ms}$ visual mask, and then a blank screen varying between $1640-1840 \mathrm{~ms}(M=1744 \mathrm{~ms})$ allowed for the subject's response. The stimuli were presented using the E-Prime 2.0 software (Psychology Software Tools, Inc., http://www.pstnet.com/ PA, USA). The same stimulus list of 320 was used once in the supraliminal mode and once in the subliminal mode. This yielded a total list of 640 randomly intermixed stimuli (half to be presented for $240 \mathrm{~ms}$ and the other half for $33 \mathrm{~ms}$ ) which were then divided into four equivalent blocks of 160 words each. The order of the blocks was balanced over participants. The Participants were asked to make their decisions (whether the stimulus was a "word" or a "pseudoword") as quickly and accurately as possible, and when not sure to guess. The participants responded using keyboard keypresses $(4 / 5)$, with the middle and index fingers of their dominant right hand. The use of 
keypresses (with the middle and index fingers) was also counterbalanced over participants in order to avoid possible finger effects. The reaction time (relative to stimulus onset) and the accuracy for every stimulus were recorded for offline analysis.

As mentioned above, the DR participants were tested during the habitual schooldays, in a quiet room dedicated specially for the study. All the students participated to this study after giving their written consent. The DR participants and their matched controls were first tested in separate session for the screening tests (see Table 2). For the LDT, the participants (DRs and NRs) were tested in a second session that lasted $\sim 35$ minutes (with breaks), starting with the lexical decision experiment followed by the SRT and DRT task. All participants were first asked fill a questionnaire to specify their full name, age, gender, years of schooling, and dominant hand as identification information and to provide written consent. Before running the LDT experiment, the participants were provided with the full instructions for each presentation mode, supplied in spoken Arabic, and undertook a training session of about 40 trial in order to ensure a full understanding of the task demands.

\subsection{Statistical Analysis}

The mean of the individual reaction times (RTs, in $\mathrm{ms}$ ) and the individual percentage of correct responses were computed separately for each of the two presentation modes (supra- vs. subliminal) and word types (or lexicality: W vs. PW). Also, the analysis of the errors in pseudoword conditions (i.e., false alarms for word conditions) allowed the computation of the $d$ from signal detection theory

Table 2. Mean response times (in sec, and SD) and accuracy (\% Correct Responses, and SD) for DR and NR on Reading Tests (Words, Pseudowords, Text) and phonological tests (Segmentation and RAN). Unpaired t-tests were used to assess the difference between the two groups (Note ${ }^{\star} p<0.05,{ }^{\star *} p<0.01,{ }^{\star * *} p<0.001$ ).

\begin{tabular}{|c|c|c|c|c|c|c|}
\hline \multirow[b]{2}{*}{ Measures } & \multicolumn{3}{|c|}{ Response times } & \multicolumn{3}{|c|}{ Accuracy } \\
\hline & NR & DR & $\mathbf{t}$ & NR & DR & $\mathbf{t}$ \\
\hline \multicolumn{7}{|c|}{ Reading tests } \\
\hline Reading vowelized PW & $\begin{array}{c}54 \\
(21)\end{array}$ & $\begin{array}{c}91 \\
(69)\end{array}$ & $2.38^{*}$ & $\begin{array}{c}83 \\
(11)\end{array}$ & $\begin{array}{c}66 \\
(15)\end{array}$ & $4.17^{* * *}$ \\
\hline Reading vowelized W & $\begin{array}{c}38 \\
(10)\end{array}$ & $\begin{array}{c}94 \\
(61)\end{array}$ & $4.15^{* * *}$ & $\begin{array}{l}89 \\
(8)\end{array}$ & $\begin{array}{c}78 \\
(14)\end{array}$ & $3.19^{* *}$ \\
\hline Oral text reading & $\begin{array}{l}133 \\
(27)\end{array}$ & $\begin{array}{c}200 \\
(103)\end{array}$ & $2.89^{* *}$ & $\begin{array}{l}99 \\
(1)\end{array}$ & $\begin{array}{c}66 \\
(10) \\
\end{array}$ & $14.92^{* * *}$ \\
\hline \multicolumn{7}{|c|}{ Phonological tests } \\
\hline PW phon. awareness & $\begin{array}{l}127 \\
(37)\end{array}$ & $\begin{array}{l}154 \\
(30)\end{array}$ & $2.62^{\star}$ & $\begin{array}{c}80 \\
(19)\end{array}$ & $\begin{array}{c}45 \\
(22)\end{array}$ & $5.58^{* * *}$ \\
\hline W phon. awareness & $\begin{array}{l}108 \\
(24)\end{array}$ & $\begin{array}{l}142 \\
(37)\end{array}$ & $3.57^{\star *}$ & $\begin{array}{c}86 \\
(16)\end{array}$ & $\begin{array}{c}44 \\
(18)\end{array}$ & $7.82^{* * *}$ \\
\hline RAN & $\begin{array}{l}25 \\
(4)\end{array}$ & $\begin{array}{l}33 \\
(9)\end{array}$ & $3.89^{* * *}$ & --- & --- & --- \\
\hline
\end{tabular}


(see for details Green \& Swets, 1966; Macmillan \& Creelman, 1991). The $d$ is a discrimination measure allowing verification of the participants' response strategies and the validity of their responses. This measure was computed for each participant in the word conditions on the basis of the hit and false alarm rates in word conditions. The $d$ is a discriminability index (i.e., how discriminable the signal is from no-signal (see for details:

http://www.cns.nyu.edu/ david/handouts/sdt/sdt.html by Professor David Heeger, 2003, New York University). This measure is unbiased and independent of the adoption of a criterion by the participant (i.e., the criterion or the tendency to answer yes or no under a given condition of visibility). A $d$ value of " 0 " points to the inability to discriminate a signal from noise and larger values point to a greater ability to differentiate signal from noise (Heeger, 1997). In order to compare these measures statistically, repeated measures analyses of variance (ANOVA) were performed using group as between participants' factor (NR vs. DR), and presentation mode (supra- vs. subliminal) and lexicality (word vs. pseudoword) as within-participants factors.

\section{Results}

\subsection{Screening Tests}

The scores of the DR participants in the different screening tests were statistically compared with those of an age-matched control group of NR (see Table 2) using t-tests for independent groups. These comparisons showed that DRs were slower than NRs in terms of response times and showed lower accuracy in reading vowelized pseudowords and words and in text reading. They also showed slower response times and lower accuracy in phonological segmentation of words and pseudowords. In the tests assessing the speed of information processing (RAN), naming letters, digits and pictures was performed significantly slower in DR than in NR (see Table 2, for means and SD over participants).

It shows that the DR exhibited globally slower RTs (by about $35 \mathrm{~ms}$ ) than NR in the two computerized tasks. Also, it shows that mixing two conditions ( $\mathrm{X}$ and $\mathrm{Y}$ in DRT) caused similar costs to both groups. This observation was confirmed by a $2 \times 3$ repeated measure analysis of variance (ANOVA) performed on the individual median RTs using group as between participants' factor (NR vs. DR) and stimulus ( $\mathrm{X}$ symbol in SRT, $\mathrm{X}$ and $\mathrm{Y}$ symbols in DRT) as within subject factors. This analysis revealed a significant main effect of group $(F(1,72)=7.22, p$ $\left.<0.01, \eta^{2}=0.091\right)$ due to slower RTs in DRs $(M=404, S E=10.9)$ than in NRs $(M=369, S E=6.9)$. There was also a highly significant effect of stimulus $(F(2$, $144)=415.6, p<0.00001, \eta^{2}=0.852$ ), due to the fact that responses (for both $\mathrm{X}$ and $\mathrm{Y}$ ) in DRT were about $180 \mathrm{~ms}$ longer than in SRT. No interaction was observed between the two factors $\left(F(2,144)=0.38, p=0.684, \eta^{2}=0.005\right)$. The $2 \times$ 3 ANOVA performed on the percent of correct responses showed only a main effect of stimulus $\left(F(2,144)=34.7, p<0.00001, \eta^{2}=0.325\right)$. This was due to the fact that responses to $\mathrm{X}$ and $\mathrm{Y}$ in the DRT yielded a lower accuracy than $\mathrm{X}$ in the 
SRT (post-hoc LSD Fisher's tests: $p<0.00001$ ), and also Y yielded lower accuracy than X in the DRT $(p<0.002)$ (Table 3$)$.

\subsection{Reaction Times Analysis during Lexical Decision}

The means (and standard deviation, $\mathrm{SD}$ ) of the individual reaction times (RTs), of the individual percentages of correct responses and of the $d$ detection values over participants of each group, for each condition are presented in Table 4 \& Table 5 . The $2 \times 2 \times 2$ ANOVA performed on the individual RTs used group as between participants' factor (NR vs. DR), and presentation mode (supra- vs. subliminal) and lexicality (word vs. pseudoword) as within participant factors. As shown in Table 4, this analysis showed a marginally significant effect of group $\left(\mathrm{F}(1,78)=3.25, p=0.076, \eta^{2}=0.040\right)$ due to longer RTs in the DR $(M=$ $707 \mathrm{~ms}, S E=20.7)$ than in the NR $(M=664 \mathrm{~ms}, S E=12.3)$. A significant main effect of presentation was found $\left(\mathrm{F}(1,78)=6.30, p=0.015, \eta^{2}=0.075\right)$ due to a shorter RTs in the subliminal $(M=668 \mathrm{~ms}, S E=11.5)$ than in the supraliminal presentation $(M=702 \mathrm{~ms}, S E=15.8)$. A highly significant effect of lexicality was found $\left(\mathrm{F}(1,78)=92.65, p=0.00001, \eta^{2}=0.543\right)$ due to shorter RTs to words $(M$ $=643 \mathrm{~ms}, S E=11.1)$ than to pseudowords $(M=727 \mathrm{~ms}, S E=14.3)$. In addition, significant two-way interactions were found between presentation type and group $\left(F(1,78)=9.06, p=0.004, \eta^{2}=0.104\right)$, presentation type and lexicality $(F$ $\left.(1,78)=33.8, p<0.00001, \eta^{2}=0.302\right)$ and between lexicality and group $(F(1$, $\left.78)=17.2, p<0.0001, \eta^{2}=0.181\right)$. Although no significant three-way interaction was found, the fact that the presentation type factor interacted with the two other

Table 3. Means, reaction time (in ms, and SD), accuracy (\% correct responses, and SD) in simple reaction time (SRT) and double reaction time (DRT) tasks. Note that in SRT the participant had to respond to one stimulus only (X) while in the DRT they had to respond randomly either to $\mathrm{X}$ or to $\mathrm{Y}$.

\begin{tabular}{ccccccc}
\hline & \multicolumn{3}{c}{ Normal readers } & \multicolumn{3}{c}{ Disabled readers } \\
\hline & SRT & \multicolumn{2}{c}{ DRT } & SRT & DRT \\
\hline Symbol & X & X & Y & X & X & Y \\
\hline RT & 244 & 428 & 434 & 287 & 460 & 466 \\
(ms) & $(58)$ & $(63)$ & $(53)$ & $(70)$ & $(64)$ & $(61)$ \\
Accuracy (\%) & 98 & 96 & 94 & 99 & 94 & 92 \\
& $(7)$ & $(7)$ & $(9)$ & $(2)$ & $(5)$ & $(8)$ \\
\hline
\end{tabular}

Table 4. Mean reaction time (in ms, and SD) in the LDT for the different experimental conditions as a function of group (NR vs. DR), of lexicality (words vs. pseudowords, here $\mathrm{W}$ and $\mathrm{PW}$ ), and of presentation mode (supraliminal vs. subliminal).

\begin{tabular}{ccccc}
\hline & \multicolumn{2}{c}{ Normal readers } & \multicolumn{2}{c}{ Disabled readers } \\
\hline & Supraliminal & Subliminal & Supraliminal & Subliminal \\
\hline \multirow{2}{*}{ W } & 642 & 696 & 688 & 680 \\
& $(103)$ & $(95)$ & $(133)$ & $(115)$ \\
\multirow{2}{*}{ PW } & 738 & 698 & 847 & 743 \\
& $(139)$ & $(110)$ & $(187)$ & $(136)$ \\
\hline
\end{tabular}


Table 5. Accuracy (\% correct responses, SD) and $d$ value in LDT, for the different experimental conditions as a function of group (NR vs. DR), of lexicality (words vs. pseudowords, here $\mathrm{W}$ and $\mathrm{PW}$ ), and of presentation mode (supraliminal vs. subliminal). K-S for Kolmogorov-Smirnov one-sample test for normality.

\begin{tabular}{|c|c|c|c|c|c|}
\hline & & \multicolumn{2}{|c|}{ Normal readers } & \multicolumn{2}{|c|}{ Disabled readers } \\
\hline & & Supraliminal & Subliminal & Supraliminal & Subliminal \\
\hline & $\mathrm{W}$ & $\begin{array}{c}0.94 \\
(0.05)\end{array}$ & $\begin{array}{l}0.56 \\
(0.2)\end{array}$ & $\begin{array}{c}0.87 \\
(0.06)\end{array}$ & $\begin{array}{c}0.59 \\
(0.22)\end{array}$ \\
\hline Accuracy & PW & $\begin{array}{c}0.91 \\
(0.07)\end{array}$ & $\begin{array}{c}0.70 \\
(0.15)\end{array}$ & $\begin{array}{c}0.73 \\
(0.14)\end{array}$ & $\begin{array}{c}0.56 \\
(0.17)\end{array}$ \\
\hline$d$ value & & $\begin{array}{c}3.26 \\
(0.82)\end{array}$ & $\begin{array}{c}0.79 \\
(0.62)\end{array}$ & $\begin{array}{c}1.85 \\
(0.70)\end{array}$ & $\begin{array}{c}0.42 \\
(0.44)\end{array}$ \\
\hline$d$ normality (K-S) & & $\begin{array}{c}d=0.069 \\
p>0.20\end{array}$ & $\begin{array}{c}d=0.075 \\
p>0.20\end{array}$ & $\begin{array}{c}d=0.133 \\
p>0.20\end{array}$ & $\begin{array}{c}\mathrm{d}=0.199 \\
\mathrm{p}>0.20\end{array}$ \\
\hline
\end{tabular}

factors (group and lexicality, interacting also between them) motivated conducting separate $2 \times 2$ ANOVAs for each presentation mode, using the lexicality and group factors.

RTs in the supraliminal presentation mode: The $2 \times 2$ ANOVA showed a significant main effect of group $\left(F(1,78)=5.8, p<0.02, \eta^{2}=0.069\right)$ due to longer RTs in the DR $(M=768 \mathrm{~ms})$ than in the NR $(M=690 \mathrm{~ms})$. A highly significant main effect of lexicality was seen again $(F(1,78)=167.9, p<0.00001$, $\left.\eta \mathrm{p}^{2}=0.683\right)$ due to shorter RTs to words $(M=654 \mathrm{~ms}$ ) than to pseudowords ( $M$ $=766 \mathrm{~ms})$. In addition, a significant interaction was found between lexicality and group $\left(F(1,78)=10.3 p<0.002, \eta^{2}=0.116\right)$. This interaction was due to the fact that the difference in RTs between words and pseudowords was much larger in DR (by $159 \mathrm{~ms}, p<0.00001$ ) than in NR (by $96 \mathrm{~ms}, p<0.00001$ ), and also to the fact that only pseudowords differed between groups $\left(p<0.02, \eta^{2}=0.093\right)$ but not words $\left(p=0.31, \eta^{2}=0.034\right)$.

$\mathrm{RT}$ in the subliminal presentation mode: The $2 \times 2$ ANOVA showed only a main effect of lexicality $\left(F(1,78)=8.5, p<0.002, \eta^{2}=0.098\right)$ due again to shorter RTs in words $(M=692 \mathrm{~ms})$ than in pseudowords $(M=710 \mathrm{~ms})$. In addition, a significant interaction was found between group and lexicality $(F(1,78)$ $=7.3, p<0.01, \eta^{2}=0.086$ ). This interaction was due to the fact that the lexicality effect (W vs. PW) was significant only in the DR (LSD post-hoc tests, $p<0.002$, $\left.\eta^{2}=0.259\right)$ but not in the NR $\left(p=0.84, \eta^{2}=0.001\right)$.

\subsection{Detection Measure ( $d$ ') Analysis during Lexical Decision}

In this paradigm, performance was established on the basis of the $d^{p}$ detection measure from signal detection theory (see Methods). This detection (or sensitivity) was computed for each participant using the hit and false alarm rates. The resulting mean $d$ values are presented in Table 5 together with descriptive statistics for accuracy as a function of presentation type and group. Before comparing statistically the individual $d^{\prime}$ 'values, we first verified the normality of the 
samples using the Kolmogorov-Smirnov one-sample test. As shown in Table 5 (bottom row), data were confirmed to be normally distributed in each presentation type and group. We then verified that the $d^{d}$ values in the subliminal mode were significantly above zero $(\mathrm{t}(58)=9.77 p<0.001)$ for NRs and $(\mathrm{t}(20)=4.33 p$ $<0.001)$ for DRs) suggesting a non-random response mode on average in both groups. Finally, we computed the correlation between the individual $d$ values in each group between the two presentation modes. This analysis showed that the individual scores positively correlated between the two modes in NR ( $d$ Subliminal $=-0.7931+0.48539 * d$ Supraliminal; $r=0.64, p<0.001)$ and in $\mathrm{RD}(d$ Subliminal $=-0.1620+0.31343 * d$ Supraliminal; $r=0.49, p<0.03$ ).

A $2 \times 2$ ANOVA was then conducted on $d$ values using group as betweenparticipants' factor, and presentation mode as within-participant factor. It showed first a highly significant main effect of group $\left(F(1,78)=32.1, p<0.00001, \eta^{2}=\right.$ $0.291)$ due to higher detection in NR $(M=2.03, S E=0.08)$ than in DR $(M=$ $1.14, S E=0.135)$. A main effect of presentation mode was also found $(F(1,78)=$ 592.5, $\left.p<0.00001, \eta^{2}=0.884\right)$ due to higher detection in supra- $(M=2.56, S E=$ $0.101)$ than in subliminal presentation $(M=0.605 \mathrm{~ms}, S E=0.074)$. In addition, a significant interaction was observed between presentation and group $(F(1,78)=$ $41.9, p<0.00001, \eta^{2}=0.349$ ), due to the fact that the difference between groups was much larger in the supra- than in the subliminal presentation. In order to further assess these effects and verify the study hypotheses, this interaction was decomposed into two separate one way ANOVAs for each of the presentation modes. In the supraliminal presentation mode, this analysis revealed a highly significant effect of group $(F(1,78)=49.0, p<0.0001$, Cohen's $d=1.77$ and effect-size $r=0.663$ ) due to higher detection by NRs than by DRs with. In the subliminal presentation mode, the difference was smaller but still showed a significant effect of group $(F(1,78)=6.35, p<0.02$, Cohen's $d=0.74$ and effect-size $r$ $=0.349)$. According to Cohen $(1988,1992$, cited in McLeod, 2019), an effect size is considered medium if the $r$ value is around 0.3, and large if the $r$ is higher than 0.5. The results reported here indeed showed that the large effect found in the supraliminal mode between the two groups decreased and turned to be of medium size in the subliminal mode.

\section{Discussion}

The present study aimed at examining visual word recognition in Arabic among adult skilled normal readers (NR) and disabled readers (DR) using masked subliminal and supraliminal word presentations in a lexical decision task (LDT). We assumed that DR would exhibit slower reaction times (RTs) and lower performance than skilled normal readers (NR), particularly under supraliminal conditions, given that their slowness is a characteristic limitation of their reading abilities. Also, we postulated that subliminal presentations would reduce the differences in performance (analyzed here in terms of $d$ measures) between DR and NR due to the fact that in both groups, the participants would identify words by 
relying on advanced orthographic rather than phonological skills.

The performance of DRs in screening tests, undertaken prior to the LDT experiment, showed significantly low scores in the various reading and phonological tests. These disadvantages were shown both in response times and performance and were also found in other tests including the speed of information processing (RAN tests). The performance in these tests was shown to predict slowness in word recognition process (e.g., Manis, 1985; Bowers \& Wolf 1993; Felton \& Wood, 1989). In addition, we found that DRs exhibited slower response times than NRs in both the simple reaction time task (SRT) and in the double reaction time task (DRT) tasks. Taken together, the screening tests confirmed that DR participants, selected on the basis of a previous institutional examination or on their teachers' reports, were actually impaired regarding their reading and phonological abilities but also in terms of their speed of processing abilities.

As expected in this type of paradigm, we observed a word superiority or lexicality effect (Coch \& Mitra, 2010; Coltheart et al., 2001). This was revealed here in the RT difference between words and pseudowords, independent of the readers' groups, where words yielded shorter RTs than pseudowords. This is likely due to the nature of words that can be read and named through a direct access to the lexicon, whereas achieving pronunciation of pseudowords would be of a more complex nature due to the longer and less efficient process of the prelexical phonological components (Coltheart, 2005). This finding fits with observations from several previous studies (Coltheart, 2005), including in the Arabic language, using LDTs in adult NR and DR but also in children (e.g., Abu-Rabia et al., 2003; Bentin \& Ibrahim, 1996; Khateb et al., 2013; Khateb et al., 2014).

In our study, an interaction between lexicality and group was observed, showing a greater lexicality effect among DRs in comparison with NRs, a result which fits with their core deficit in reading tasks and phonological processing. This finding was observed in the supraliminal presentation and in the subliminal presentation. The presence in the DR group of the lexicality effect in subliminal presentations, showing that identifying real words occurs faster than pseudowords, is of particular importance in this study. The fact that this effect is still observed in the DR group would indicate that they have certain efficient orthographic capabilities, allowing them to use the visual-orthographic lexical route. This finding is in line with other studies in Arabic (Abu-Rabia et al., 2003), where it had been claimed that DRs had good orthographic skills as NRs, allowing them to compensate for their deficit in phonological word recognition.

Regarding the group effects more generally, the NR group was faster and more accurate than the DR group, especially in the supraliminal presentation mode. The $d$ values in the supraliminal mode were in both groups significantly higher than in the subliminal one, as expected (e.g., Pegna et al., 2008; Van den Bussche et al., 2009). The comparison of the DR and the NR groups in terms of detection, as a function of the presentation mode, showed that the gap between 
groups in real word detection was reduced, as attested by the group effect size (partial eta squared values: $\eta p^{2}=0.39 v s . \eta p^{2}=0.07$ ) which decreased in the subliminal presentation mode relative to the supraliminal mode. This finding would suggest that the DR group, who relied on inefficient phonological decoding processes during supraliminal presentation, was better assisted by whole word pattern identification in the subliminal mode rather than by phonological decoding strategies (Leinonen et al., 2001). This finding was supported in part by the fact that a discrete difference was observed in RTs in the DR group where reaction times appeared somewhat faster in the subliminal mode than the supraliminal. Such data are in agreement with Layes, Lalonde, Mecheri, \& Rebaï (2015) who measured the speed and accuracy of reading among Arabic-speaking phonological and mixed dyslexic children matched with controls for the age of 8 - 10. In this study the participants were given single frequent and infrequent word and pseudo-word reading and phonological awareness tasks. Lower scores among the group with dyslexia than controls in accuracy and reading speed tasks were observed in the results. This could have been contributed due to the fact that efficient readers relied on the lexical route, whereas the dyslexic group was unable to compensate for the phonological deficit with a lexical strategy. Instead they utilized a sub-lexical (phonological) strategy for reading infrequent as well as frequent words, whereby each grapheme must be serially processed, thereby slowing the process.

The effect of word type in the detection measure was also shown in previous studies (e.g., Kroll \& Merves, 1986; Schwanenflugel, 1991) where concrete words had a higher detection rate than abstract words, especially in the supraliminal mode. Surprisingly, and in contrast to these previous studies, it was observed here that the abstract words were faster than the concrete ones only in the subliminal presentation mode, and particularly in the DR group. Further research is needed to verify whether or not abstract words represent a particular category for DRs.

In conclusion, the results of this study corroborated previous reports in this field. Our findings can constitute a reasonable recommendation to all educators in general and to the special education professionals in particular, on how to deal with younger disabled readers. As mentioned in this study, the disabled readers have a phonological deficit that may be improved by strengthening their orthographic processing skills in order to achieve more automatized word recognition processes using for instance word flashing task and word profiling tasks. In this respect, previous and recent studies showed that speeding reading tasks improved reading abilities in DRs (Zvia). This process would also be more successful by enhancing working memory which should be another priority for improving reading abilities in disabled readers. Finally, educators should try to further enlarge the reader's word lexicon by exposing them to a greater orthographic variety and larger vocabulary to improve their reading capability.

For instance, Abu-Rabia et al. (2003) reported that the performance of read- 
ing-disabled children on orthographic processing measures was as good as that of the NRs. As suggested previously by others (Siegel, Share, \& Geva, 1995), the authors also pointed out that reading-disabled adults rely on the visual-orthographic route (i.e., the lexical) to compensate for their phonological difficulties during word recognition, due to the orthographic features of the Arabic system (Abu-Rabia et al, 2003).

\section{Conflicts of Interest}

The authors declare no conflicts of interest regarding the publication of this paper.

\section{References}

Abu-Rabia, S., \& Siegel, L. S. (2002). Reading, Syntactic, Orthographic, and Working Memory Skills of Bilingual Arabic-English Speaking Canadian Children. Journal of Psycholinguistic Research, 31, 661-678.

Abu-Rabia, S., Share, D., \& Mansour, M. S. (2003). Word Recognition and Basic Cognitive Processes among Reading-Disabled and Normal Readers in Arabic. Reading and Writing, 16, 423-442. https://doi.org/10.1023/A:1024237415143

Ben-Dror, I., Pollatsek, A., \& Scarpati, S. (1991). Word Identification in Isolation and in Context by College Dyslexic Students. Brain and Language, 40, 471-490. https://doi.org/10.1016/0093-934X(91)90144-P

Bentin, S., \& Ibrahim, R. (1996). New Evidence for Phonological Processing during Visual Word Recognition: The Case of Arabic. Journal of Experimental Psychology: Learning, Memory, and Cognition, 22, 309-323. https://doi.org/10.1037/0278-7393.22.2.309

Bowers, P. G., \& Wolf, M. (1993). Theoretical Links among Naming Speed, Precise Timing Mechanisms and Orthographic Skill in Dyslexia. Reading and Writing, 5, 69-85. https://doi.org/10.1007/BF01026919

Bowey, J. A., \& Muller, D. (2005). Phonological Recoding and Rapid Orthographic Learning in Third-Graders' Silent Reading: A Critical Test of the Self-Teaching Hypothesis. Journal of Experimental Child Psychology, 92, 203-219.

https://doi.org/10.1016/j.jecp.2005.06.005

Bruck, M. (1992). Persistence of Dyslexics' Phonological Awareness Deficits. Developmental Psychology, 28, 874-886. https://doi.org/10.1037/0012-1649.28.5.874

Cleeremans, A., \& McClelland, J. L. (1991). Learning the Structure of Event Sequences. Journal of Experimental Psychology: General, 120, 235. https://doi.org/10.1037/0096-3445.120.3.235

Coch, D., \& Mitra, P. (2010) Word and Pseudoword Superiority Effects Reflected in the ERP Waveform. Brain Research, 1329, 159-174.

https://doi.org/10.1016/j.brainres.2010.02.084

Coltheart, M., Rastle, K., Perry, C., Langdon, R., \& Ziegler, J. (2001). DRC: A Dual Route Cascaded Model of Visual Word Recognition and Reading Aloud. Psychological Review, 108, 204-256. https://doi.org/10.1037/0033-295X.108.1.204

Coltheart, M. (2005). Modeling Reading: The Dual-Route Approach. The Science of Reading: A Handbook, 6, 23-41. https://doi.org/10.1002/9780470757642.ch1

Dehaene, S., Naccache, L., Cohen, L., Bihan, D. L., Mangin, J. F., Poline, J. B., \& Riviere, D. (2001). Cerebral Mechanisms of Word Masking and Unconscious Repetition Priming. Nature Neuroscience, 4, 752-758. https://doi.org/10.1038/89551 
Denckla, M. B., \& Rudel, R. G. (1976). Rapid “Automatized” Naming (RAN): Dyslexia Differentiated from Other Learning Disabilities. Neuropsychologia, 14, 471-479. https://doi.org/10.1016/0028-3932(76)90075-0

Elbro, C., Nielsen, I., \& Petersen, D. K. (1994). Dyslexia in Adults: Evidence for Deficits in Non-Word Reading and in the Phonological Representation of Lexical Items. Annals of Dyslexia, 44, 203-226. https://doi.org/10.1007/BF02648162

Enns, J. T., \& Di Lollo, V. (2000). What's New in Visual Masking? Trends in Cognitive Sciences, 4, 345-352. https://doi.org/10.1016/S1364-6613(00)01520-5

Felton, R. H., \& Wood, F. B. (1989). Cognitive Deficits in Reading Disability and Attention Deficit Disorder. Journal of Learning Disabilities, 22, 3-13. https://doi.org/10.1177/002221948902200102

Fletcher, J. M. (2009). Dyslexia: The Evolution of a Scientific Concept. Journal of the International Neuropsychological Society: JINS, 15, 501-508. https://doi.org/10.1017/S1355617709090900

Fairhall, S. L., Hamm, J. P., \& Kirk, I. J. (2007). Temporal Dynamics of Masked Word Reading. Consciousness and Cognition, 16, 112-123. https://doi.org/10.1016/j.concog.2006.01.002

Gaillard, R., Del Cul, A., Naccache, L., Vinckier, F., Cohen, L., \& Dehaene, S. (2006). Nonconscious Semantic Processing of Emotional Words Modulate Conscious Access. Proceedings of the National Academy of Sciences United States of America, 103, 7524-7529. https://doi.org/10.1073/pnas.0600584103

Green, D. M., \& Swets, J. A. (1966). Signal Detection Theory and Psychophysics (Vol. 1). New York: Wiley.

Heeger, D. (2003). Signal Detection Theory. http://www.cns.nyu.edu/ david/sdt/sdt.html

Heeger, D. (1997). Signal Detection Theory, Teaching Handout. Department of Psychology.

Khateb, A., Khateb-Abdelgani, M., Taha, H. Y., \& Ibrahim, R. (2014). The Impact of Orthographic Connectivity on Visual Word Recognition in Arabic: A Cross-Sectional Study. Reading and Writing, 27, 1413-1436. https://doi.org/10.1007/s11145-014-9499-y

Khateb, A., Taha, H. Y., Elias, I., \& Ibrahim, R. (2013). The Effect of the Internal Orthographic Connectivity of Written Arabic Words on the Process of the Visual Recognition: A Comparison between Skilled and Dyslexic Readers. Writing Systems Research, 5, 214-233. https://doi.org/10.1080/17586801.2013.834244

Kiesel, A., Wagener, A., Kunde, W., Hoffmann, J., Fallgatter, A. J., \& Stöcker, C. (2006). Unconscious Manipulation of Free Choice in Humans. Consciousness and Cognition, 15, 397-408. https://doi.org/10.1016/j.concog.2005.10.002

Kouider, S., \& Dehaene, S. (2007). Levels of Processing during Non-Conscious Perception: A Critical Review of Visual Masking. Philosophical Transactions of the Royal Society B: Biological Sciences, 362, 857-875. https://doi.org/10.1098/rstb.2007.2093

Kroll, J. F., \& Merves, J. S. (1986). Lexical Access for Concrete and Abstract Words. Journal of Experimental Psychology: Learning, Memory, and Cognition, 12, 92-107. https://doi.org/10.1037/0278-7393.12.1.92

Layes, S., Lalonde, R., Mecheri, S., \& Rebaï, M. (2015). Phonological and Cognitive Reading Related Skills as Predictors of Word Reading and Reading Comprehension among Arabic Dyslexic Children. Psychology, 6, 20-38. https://doi.org/10.4236/psych.2015.61003

Lefly, D. L., \& Pennington, B. F. (1991). Spelling Errors and Reading Fluency in Compensated Adult Dyslexics. Annals of Dyslexia, 41, 143-162. 
https://doi.org/10.1007/BF02648083

Leinonen, S., Müller, K., Leppänen, P. H., Aro, M., Ahonen, T., \& Lyytinen, H. (2001). Heterogeneity in Adult Dyslexic Readers: Relating Processing Skills to the Speed and Accuracy of Oral Text Reading. Reading and Writing, 14, 265-296. https://doi.org/10.1023/A:1011117620895

Macmillan, N. A., \& Creelman, C. D. (1991). Detection Theory: A User's Guide. Cambridge: Cambridge University Press.

Manis, F. R. (1985). Acquisition of Word Identification Skills in Normal and Disabled Readers. Journal of Educational Psychology, 77, 78-90. https://doi.org/10.1037/0022-0663.77.1.78

Miller-Shaul, S. (2005). The Characteristics of Young and Adult Dyslexics Readers on Reading and Reading Related Cognitive Tasks as Compared to Normal Readers. Dyslexia, 11, 132-151. https://doi.org/10.1002/dys.290

McLeod, S. A. (2019). What Does Effect Size Tell You? Simply Psychology. https://www.simplypsychology.org/effect-size.html

McPherson, W. B., Ackerman, P. T., Holcomb, P. J., \& Dykman, R. A. (1998). Event-Related Brain Potentials Elicited during Phonological Processing Differentiate Subgroups of Reading Disabled Adolescents. Brain and Language, 62, 163-185. https://doi.org/10.1006/brln.1997.1893

Ocampo, B. (2015). Unconscious Manipulation of Free Choice by Novel Primes. Consciousness and Cognition, 34, 4-9. https://doi.org/10.1016/j.concog.2015.03.007

Olson, R., Forsberg, H., Wise, B., \& Rack, J. (1994). Measurement of Word Recognition, Orthographic, and Phonological Skills.

Pratt, A. C., \& Brady, S. (1988). Relation of Phonological Awareness to Reading Disability in Children and Adults. Journal of Educational Psychology, 80, 319.

https://doi.org/10.1037/0022-0663.80.3.319

Pegna, A. J., Landis, T., \& Khateb, A. (2008). Electrophysiological Evidence for Early Non-Conscious Processing of Fearful Facial Expressions. International Journal of Psychophysiology, 70, 127-136. https://doi.org/10.1016/j.ijpsycho.2008.08.007

Ruch, S., Züst, M. A., \& Henke, K. (2016). Subliminal Messages Exert Long-Term Effects on Decision-Making. Neuroscience of Consciousness, 2016, 1-9. https://doi.org/10.1093/nc/niw013

Schwanenflugel, P. J. (1991). Why Are Abstract Concepts Hard to Understand. The Psychology of Word Meanings, 11, 223-250.

Shafrir, U., \& Siegel, L. S. (1994). Preference for Visual Scanning Strategies versus Phonological Rehearsal in University Students with Reading Disabilities. Journal of Learning Disabilities, 27, 583-588. https://doi.org/10.1177/002221949402700907

Shankweiler, D., Crain, S., Brady, S., \& Macaruso, P. (2017). Identifying the Causes of Reading Disability. In In P. Gough, L. Her, \& R. Treiman (Eds.), Reading Acquisition (pp. 275-305). Mahwah, NJ: Erlbaum. https://doi.org/10.4324/9781351236904-10

Shany, M., \& Breznitz, Z. (2011). Rate- and Accuracy-Disabled Subtype Profiles among Adults with Dyslexia in the Hebrew Orthography. Developmental Neuropsychology, 36, 889-913. https://doi.org/10.1080/87565641.2011.606410

Siegel, L. S., Share, D., \& Geva, E. (1995). Evidence for Superior Orthographic Skills in Dyslexics. Psychological Science, 6, 250-254. https://doi.org/10.1111/j.1467-9280.1995.tb00601.x

Stanovich, K. E., \& Siegel, L. S. (1994). Phenotypic Performance Profile of Children with Reading Disabilities: A Regression-Based Test of the Phonological-Core Variable-Difference 
Model. Journal of Educational Psychology, 86, 24.

https://doi.org/10.1037/0022-0663.86.1.24

Suárez-Coalla, P., Ramos, S., Álvarez-Cañizo, M., \& Cuetos, F. (2014). Orthographic Learning in Dyslexic Spanish Children. Annals of Dyslexia, 64, 166-181.

https://doi.org/10.1007/s11881-014-0092-5

Taha, H., \& Saiegh-Haddad, E. (2016). The Role of Phonological versus Morphological Skills in the Development of Arabic Spelling: An Intervention Study. Journal of Psycholinguistic Research, 45, 507-535. https://doi.org/10.1007/s10936-015-9362-6

Torgesen, J. K., Wagner, R. K., Simmons, K., \& Laughon, P. (1990). Identifying Phonological Coding Problems in Disabled Readers: Naming, Counting, or Span Measures? Learning Disability Quarterly, 13, 236-243. https://doi.org/10.2307/1510350

Van den Bussche, E., Van den Noortgate, W., \& Reynvoet, B. (2009). Mechanisms of Masked Priming: A Meta-Analysis. Psychological Bulletin, 135, 452-477. https://doi.org/10.1037/a0015329

Wagner, R. K., \& Torgesen, J. K. (1987). The Nature of Phonological Processing and Its Causal Role in the Acquisition of Reading Skills. Psychological Bulletin, 101, 192. https://doi.org/10.1037/0033-2909.101.2.192

Wimmer, H. (1993). Characteristics of Developmental Dyslexia in a Regular Writing System. Applied Psycholinguistics, 14, 1-33. https://doi.org/10.1017/S0142716400010122

Wolf, M., \& Bowers, P. G. (1999). The Double-Deficit Hypothesis for the Developmental Dyslexias. Journal of Educational Psychology, 91, 415-438.

https://doi.org/10.1037/0022-0663.91.3.415 